\title{
Polymer Solar Cells with Polymer/Carbon Nanotube Composite Hole- Collecting Buffer Layers
}

\author{
Inhyuk Lee ${ }^{1}$, Seungsoo Lee ${ }^{1}$, Hwajeong Kim ${ }^{1}$, Hyunjeong Lee ${ }^{2}$ and Youngkyoo Kim*,1 \\ ${ }^{I}$ Organic Nanoelectronics Laboratory, Department of Chemical Engineering, Kyungpook National University, Daegu \\ 702-701, Republic of Korea \\ ${ }^{2}$ Hybrid Materials Research Center, Korea Institute of Science and Technology (KIST), Seoul 136-791, Republic of \\ Korea
}

\begin{abstract}
We report the performance of polythiophene/fullerene solar cells with a hole-collecting buffer layer that was made using composite films of functionalized multi-walled carbon nanotube ( $f$-MWCNT) and poly(3,4ethylenedioxythiphene):poly(styrenesulfonate) (PEDOT:PSS). The MWCNT was functionalized with carboxyl groups to bestow solubility in a weak base solvent for mixing with PEDOT:PSS. Results showed that the optical transmittance of the PEDOT:PSS/f-MWCNT composite layer coated substrate sample was slightly improved in some parts of visible and infrared regions. The polymer solar cells with the PEDOT:PSS/f-MWCNT buffer layer exhibited improved short circuit current density but other parameters became poorer than those of control device.
\end{abstract}

Keywords: Polymer solar cells, polythiophene, buffer layer, functionalized multi-walled carbon nanotube.

Polymer solar cells have been extensively studied because of their great expectations for cheap energy conversion of solar light to electricity [1-3]. Compared to all-small molecule based solar cells, polymer solar cells have advantages in terms of low-cost large area production and better flexibility (reliability under mechanical stress). In a broad sense, the final goal of polymer solar cells can be flexible and semitransparent "plastic" solar cells which can be easily attachable to windows in buildings, leading to next generation ultraslim building integrated photovoltaics (US-BIPV) [4]. In order to realize this target, the lifetime and/or reliability of polymer solar cells should be secured.

To date, most of polymer solar cells employ a holecollecting buffer layer between (transparent) electrode and active layer, whether the cell type is normal or inverted. A typical most widely used hole-collecting buffer layer is poly(3,4-ethylenedioxythiophene):poly(styrenesulfonate)

(PEDOT:PSS) [1-6]. However, the PEDOT:PSS buffer layers have a drawback owing to the lack of high optical transmittance in the deep red and infrared regions which cover over $40 \%$ photons of entire solar radiation arrived at the earth surface from sun.

Considering the intrinsic optical property of carbon nanotube (CNT) [7], CNTs can be employed to improve the optical transmittance of PEDOT:PSS layers. Although couple of studies on blending of CNT and PEDOT:PSS have been carried out for organic light-emitting devices (OLEDs), no report has been out so far for their applications to polymer solar cells [8-10].

*Address correspondence to this author at the Department of Chemical Engineering, Kyungpook National University, Sankyuk-dong, Daegu 702701, Republic of Korea; Tel: +82-53-950-5616; Fax: +82-53-950-6615;

E-mail: ykimm@knu.ac.kr
In this work, we attempted to apply composite films of CNT and PEDOT:PSS to polymer solar cells with a polythiophene/fullerene active layer. In particular, functionalized multi-walled carbon nanotubes ( $f$-MWCNT) were synthesized to secure better compatibility with PEDOT:PSS components through improving their solubility in a weak base solvent. The optical absorption and transmittance spectra were measured using the PEDOT:PSS/f-MWCNT film coated substrates. A control device with the pristine PEDOT:PSS layer was also fabricated at the same time for the investigation of device performance change.

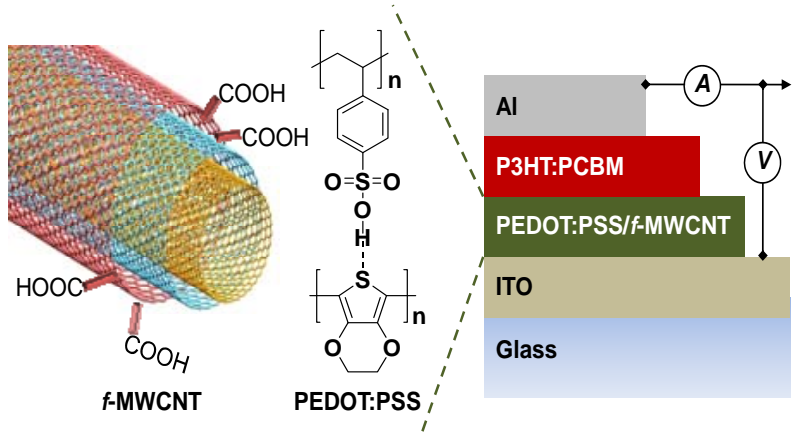

Fig. (1). Illustration of device structure and chemical structures of $f$ MWCNT and PEDOT:PSS used for hole-collecting buffer layer.

MWCNT was functionalized with carboxyl groups and dissolved in dimethylformamide (DMF) (see Fig. 1). This functionalized MWCNT ( $f$-MWCNT) was mixed with PEDOT:PSS (Clevios, PH500) at a volume ratio of 40:60 and was subject to ultrasonic treatment for well dispersion (dissolution). Regioregular poly(3-hexylthiophene) (P3HT) and 1-(3-methoxycarbonyl)-propyl-1-phenyl-(6,6) $\mathrm{C}_{61}$ (PCBM) were used as received from Rieke Metals and Na- 
no- $\mathrm{C}$, respectively. Blend solutions of $\mathrm{P} 3 \mathrm{HT}$ and $\mathrm{PCBM}$ were prepared in chlorobenzene as a solvent at a solid concentration of $60 \mathrm{mg} / \mathrm{ml}$. The pristine PEDOT:PSS and/or PEDOT:PSS/f-MWCNT blend solutions were spun onto prepatterned indium tin-oxide (ITO) coated glass substrates at $2500 \mathrm{rpm}$ for $1 \mathrm{~min}$ (we note that prior to the film coating the ITO-coated glass substrates were cleaned using acetone and isopropyl alcohol and finally cleaned with UV-ozone). The spin-coated films were annealed at $230{ }^{\circ} \mathrm{C}$ for $15 \mathrm{~min}$, leading to $\sim 80 \mathrm{~nm}$ thick buffer layer. On top of these buffer layers, P3HT:PCBM blend solutions were spun at $1500 \mathrm{rpm}$ for $30 \mathrm{sec}$ and then soft-baked at $50{ }^{\circ} \mathrm{C}$ for $15 \mathrm{~min}$. Finally, $\mathrm{Al}$ ( $100 \mathrm{~nm}$ thick) top electrodes were deposited by conventional thermal evaporation process, defining the final device structure with an active area of $0.09 \mathrm{~cm}^{2}$ (Fig. 1). The optical absorption and transmittance spectra of the buffer layers were measured using an UV-visible spectrophotometer (optizen 2120UV, Mecasys). The solar cell performance was measured using a solar cell measurement system equipped with an electrometer (Keithley 2400) and a solar simulator (Newport-Oriel). The incident light intensity was 100 $\mathrm{mW} / \mathrm{cm}^{2}$ at air mass (AM) $1.5 \mathrm{G}$ condition.

As shown in Fig. 2 (top panel), both pristine PEDOT:PSS and PEDOT:PSS/f-MWCNT films exhibited quite a similar absorption spectra in the survey scan (we note that the strong absorption at the wavelengths below $\sim 350 \mathrm{~nm}$ is owing to the ITO-glass substrates). However, the enlarged spectra showed a difference between the two spectra (see inset figure). Interestingly, the absorption intensity (optical density) became slightly higher for the PEDOT:PSS/f-MWCNT composite film than the pristine PEDOT:PSS film in the part of visible light region $(400 \sim 550 \mathrm{~nm})$. This can be attributed to the influence of light scattering because the scale of phase segregation between PEDOT:PSS and $f$-MWCNT components was not on a nanoscale (data are not shown here) so that submicron-sized aggregates were found partly in the composite film by the examination with an optical microscope. In contrast, at the wavelengths above $\sim 550 \mathrm{~nm}$, the absorption was lower for the PEDOT:PSS/f-MWCNT composite film than the pristine PEDOT:PSS film. This indicates that the PEDOT:PSS absorption was suppressed by the added $f$-MWCNT component. As a consequence, the optical transmittance in the ranges between $550 \mathrm{~nm}$ and $1110 \mathrm{~nm}$ was slightly improved at the expense of visible light transparency below $550 \mathrm{~nm}$ (Fig. 2 bottom panel).

The dark current density - voltage $(\mathrm{J}-\mathrm{V})$ characteristics are shown in Fig. (3). The device with the pristine PEDOT:PSS layer exhibited a typical dark J-V curve that is usually observed in the device with the P3HT:PCBM active layer [1-6]. In contrast, a leakage-like J-V curve was measured for the device with the PEDOT:PSS/f-MWCNT composite film at a low voltage, which might be owing to the influence of phase-segregated morphology as mentioned above because a rough surface induced by phase segregation could result in a physical leakage path because of uneven thicknesses and/or possible pin-holes. However, unlike high leakage devices, the present dark J-V curve of the device with the PEDOT:PSS/f-MWCNT composite film was not fully ohmic over the entire voltage range but showed a diode-like turn-up trend at a high voltage. Hence we conclude that the present device with the PEDOT:PSS/f-MWCNT composite film did still maintain a diode characteristic in the presence of partial
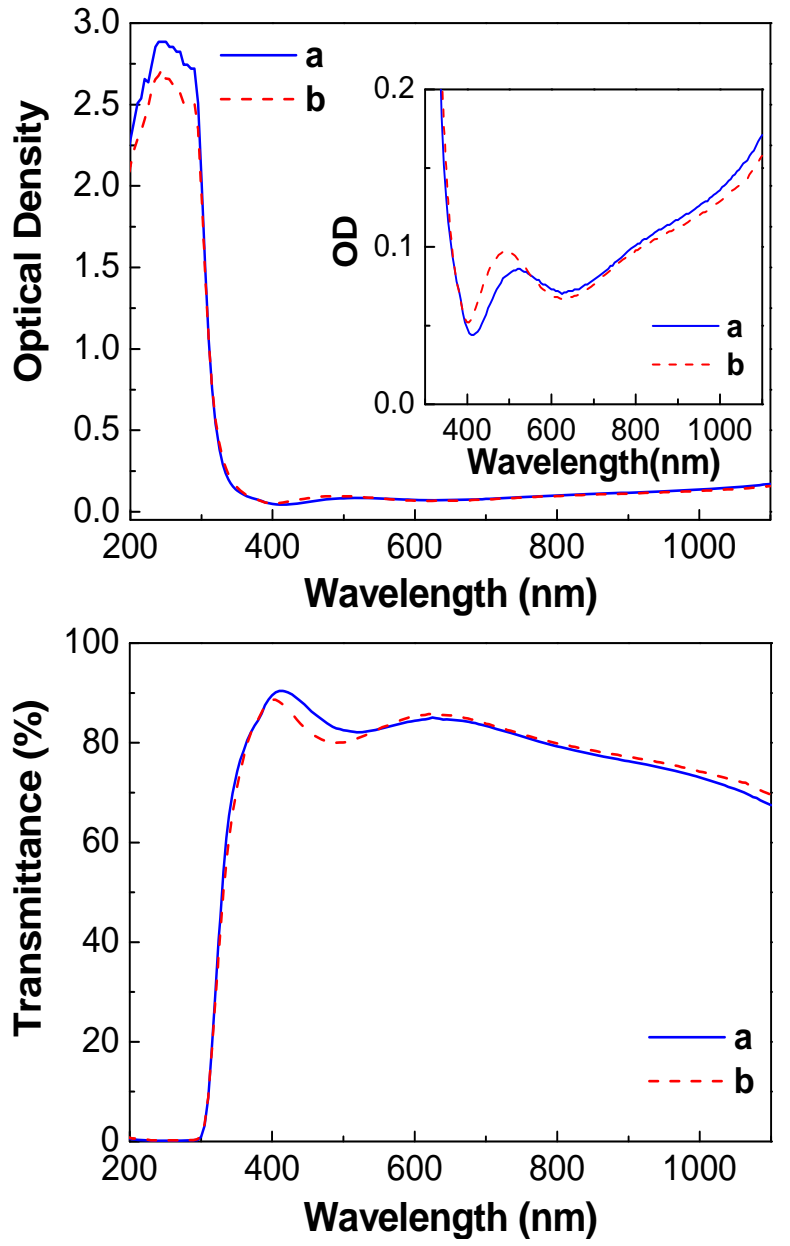

Fig. (2). Optical absorption (top) and transmittance (bottom) spectra of buffer layers coated on ITO-glass substrates: (a) PEDOT: PSS and (b) PEDOT:PSS/f-MWCNT. The inset (top panel) shows the enlarged spectra to find out the OD difference of the two samples.

leakage pathway, as observed in the inset figure that shows a high background current level.

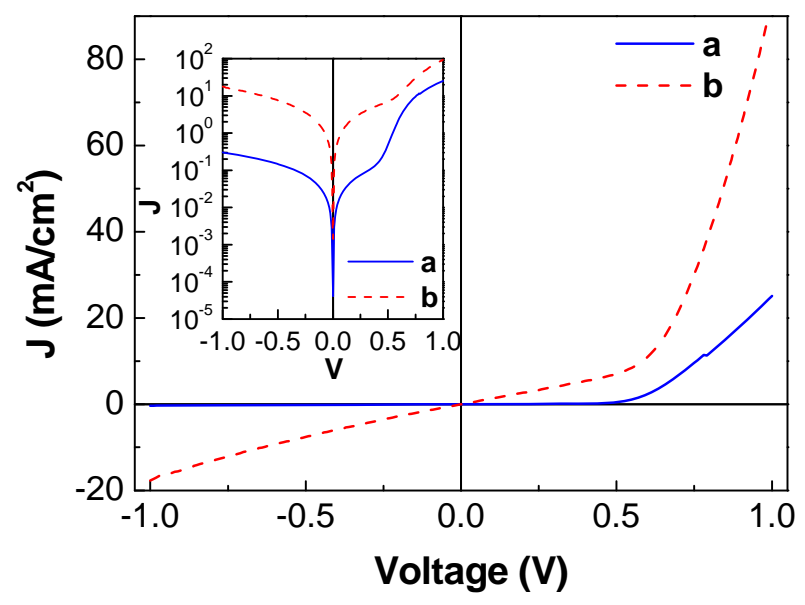

Fig. (3). Dark J-V characteristics of devices: (a) PEDOT:PSS and (b) PEDOT:PSS/f-MWCNT. Inset shows corresponding J-V curves on a semi-logarithmic scale. 


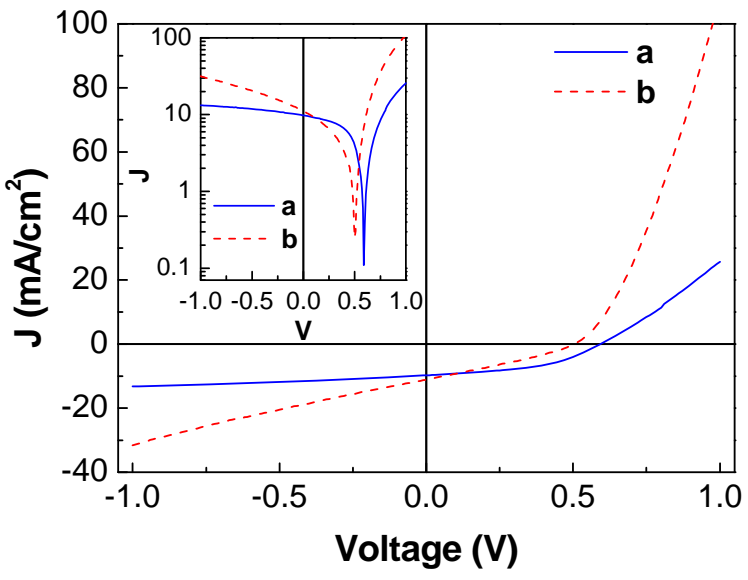

Fig. (4). Light (AM 1.5G, $100 \mathrm{~mW} / \mathrm{cm}^{2}$ ) J-V characteristics of devices: (a) PEDOT:PSS and (b) PEDOT:PSS/ $f$-MWCNT. Inset shows corresponding $\mathrm{J}-\mathrm{V}$ curves on a semi-logarithmic scale.

The light J-V characteristics are shown in Fig. (4). Compared to the control device with the pristine PEDOT:PSS layer, the device with the PEDOT:PSS/f-MWCNT composite film showed less ideal photovoltaic curve shape when it comes to the steeper slope in the $\mathrm{J}-\mathrm{V}$ curve at around short circuit condition. Interestingly, however, the short circuit current density $\left(\mathrm{J}_{\mathrm{SC}}\right)$ was higher for the device with the PEDOT:PSS/ $f$-MWCNT composite film than the device with the pristine PEDOT:PSS layer. Here we can assume that the physical leakage current can be added to the finally collected photocurrent, but it is strange to say that because physical leakage paths do normally play a decreasing role in collecting photocurrent at short circuit condition (lower voltages) owing to the harnessed charge recombination at around the leakage sites in the case of normal cells.

Table 1. Summary of Photovoltaic Parameters for the Polymer Solar Cells Made with Two Different Buffer Layers

\begin{tabular}{|c|c|c|c|c|}
\hline Buffer Layer & $\begin{array}{c}\mathbf{J}_{\mathbf{S C}} \\
\left(\mathbf{m A} / \mathbf{c m}^{2}\right)\end{array}$ & $\begin{array}{c}\mathbf{V}_{\mathbf{O C}} \\
(\mathbf{V})\end{array}$ & $\begin{array}{c}\mathbf{F F} \\
(\boldsymbol{\%})\end{array}$ & $\begin{array}{c}\text { PCE } \\
(\boldsymbol{\%})\end{array}$ \\
\hline \hline PEDOT:PSS & 9.79 & 0.59 & 46 & 2.66 \\
\hline $\begin{array}{c}\text { PEDOT:PSS/ } \\
f \text {-MWCNT }\end{array}$ & 11.15 & 0.50 & 30 & 1.65 \\
\hline
\end{tabular}

Hence, as shown in Table $\mathbf{1}$, the increased $\mathrm{J}_{\mathrm{SC}}\left(\Delta \mathrm{J}_{\mathrm{SC}}=\right.$ $\left.1.36 \mathrm{~mA} / \mathrm{cm}^{2}\right)$ of the device with the PEDOT:PSS $f$ MWCNT composite film here is considered to be contributed from other sources such as the increased interface area between the PEDOT:PSS/f-MWCNT composite film and the P3HT:PCBM active layer, the increased out-of-plane conductivity for hole collection, etc, even though the physical leakages are still not excluded. Anyhow, unfortunately, both open circuit voltage $\left(\mathrm{V}_{\mathrm{OC}}\right)$ and fill factor $(\mathrm{FF})$ were de- creased compared to the control device, which did consequently lead to the reduction in power conversion efficiency (PCE).

In summary, the influence of adding functionalized MWCNT to the PEDOT:PSS buffer layer on the performance of polymer solar cells has been briefly studied, focusing on the optical transmittance and device performance. The optical transmittance was slightly improved in the range of $550 \sim 1100 \mathrm{~nm}$ at the expense of visible light region (400 $\sim 550 \mathrm{~nm}$ ). Introducing the PEDOT:PSS/f-MWCNT composite film as a hole-collecting buffer layer resulted in the improved short circuit current density though other parameters were reduced leading to lowered power conversion efficiency. Further control of the nanomorphology of PEDOT:PSS/fMWCNT composite films is expected to enable us to improve the performance of polymer solar cells with PEDOT:PSS/f-MWCNT composite films.

\section{ACKNOWLEDGEMENTS}

This work was supported by the Korean government grants (Priority Research Center Program:2009-0093819, Pioneer Research Center Program:2009-0082820, KOSEFR01-2007-000-10836-0, KOSEF-20090072777, KETEP2008-N-PV08-J-01-30202008). Dr. H. Lee thanks a financial support by a grant from the Fundamental R\&D Program for Core Technology of Materials funded by the Ministry of Knowledge Economy, Republic of Korea.

\section{REFERENCES}

[1] Günes, S.; Neugebauer, H.; Sariciftci, N. S. Conjugated polymerbased organic solar cells. Chem. Rev. 2007, 107, 1324-1338.

[2] Thompson, B. C.; Frechet, J. M. J. Polymer-fullerene composite solar cells. Angew. Chem. Int. Ed. 2008, 47, 58-77.

[3] Dennler, G.; Scharber, M. C.; Brabec, C. J. Polymer-fullerene bulkheterojunction solar cells. Adv. Mater. 2009, 21, 1323-1338.

[4] Hauch, J. A.; Schilinsky, P.; Choulis, S. A.; Childers, R.; Biele, M.; Brabec, C. J. Flexible organic P3HT:PCBM bulk-heterojunction modules with more than 1 year outdoor lifetime. Solar Energy Mater. Solar Cells 2008, 92, 727-731

[5] Kim, Y.; Shin, M.; Kim, H. Annealing temperature effect of holecollecting polymeric nanolayer in polymer solar cells. Macromol. Res. 2008, 16, 185-188.

[6] Kim, Y.; Ballantyne, A. M.; Nelson, J.; Bradley, D. D. C. Effects of thickness and thermal annealing of the PEDOT:PSS layer on the performance of polymer solar cells. Org. Electron. 2009, 10, 205 209.

[7] Hatton, R. A.; Blanchard, N. P.; Tan, L. W.; Latini, G.; Cacialli, F.; Silva, S. Ravi P. Oxidised carbon nanotubes as solution processable, high work function hole-extraction layers for organic solar cells. Org. Electron. 2009, 10, 388-395.

[8] Chaudhary, S.; Lu, H.; Müller, A. M.; Bardeen, C. J.; Ozkan, M. Hierarchical placement and associated optoelectronic impact of carbon nanotubes in polymer-fullerene solar cells. Nano Lett. $\mathbf{2 0 0 7}$ 7, 1973-1979.

[9] Liu, D.; Fina, M.; Guo, J.; Chen, X.; Liu, G.; Johnson, S. G.; Mao, S. S. Organic light-emitting diodes with carbon nanotube cathodeorganic interface layer. Appl. Phys. Lett. 2009, 94, 013110.

[10] Oey, C. C.; Djurišic, A. B.; Kwong, C. Y.; Cheung, C. H.; Chan, W. K.; Chui, P. C. Spectroscopic ellipsometry of the optical functions of some widely used organic light emitting diodes (OLEDs) materials. Mater. Res. Soc. Symp. Proc. 2005, 871 E, I9.16.1.

(C) Lee et al.; Licensee Bentham Open.

This is an open access article licensed under the terms of the Creative Commons Attribution Non-Commercial License (http://creativecommons.org/licenses/by-nc/3.0/) which permits unrestricted, non-commercial use, distribution and reproduction in any medium, provided the work is properly cited. 